\section{INDIAN SCIENCE}

\section{Wutering the Plains}

By the year 2000, India plans to have built, from scratch, a national water grid that will ferry fresh water 1,650 miles from the shores of the Ganges to Upper Anicut on the banks of the River Cauvey in the depths of Madras. This extremely ambitious scheme, which will involve the construction of 661 miles of canal to hump the water over India's central highlands, springs from the country's unequal rainfall distribution. During the summer monsoons, water pours down the giant rivers of the north and east, flowing away to the sea, while southern, central and western India struggle through the year on markedly low rainfalls. India's answer is to build a north-south canal which will link her major rivers, all of which flow almost due east to the Bay of Bengal or due west to the Indian Ocean.

Thirty years from now, when the scheme will hopefully have been completed, ten million acres of land that is now prone to chronic drought will be under irrigation, drinking water supplies will have been stabilized throughout the country, and low cost canal transportation will link northern India to the south.

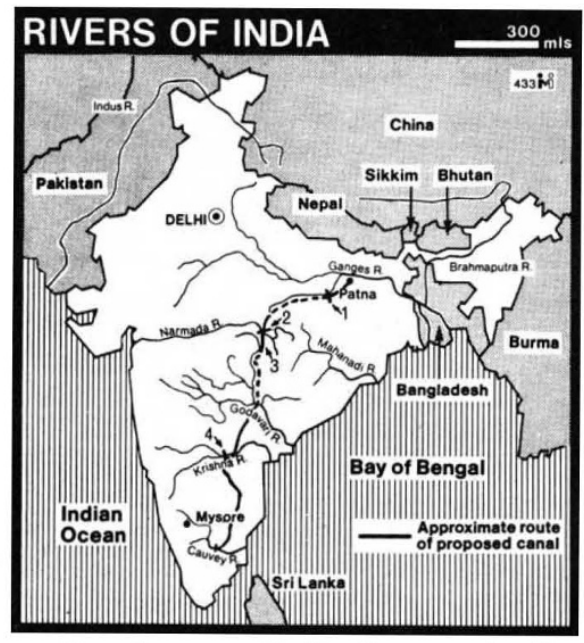

1. Sone barrage; 2. Bargi reservoir; 3 . Tunnel; 4. Srisailam reservoir.

The scheme was first mooted last century by Sir Henry Cotton, a British irrigation engineer with an eye on the low costs of canal transport, but its imminent construction is due chiefly to Dr K. L. Rao, minister for Irrigation and Power, who has seen the scheme through a United Nations feasibility study which pronounced it technically possible, and who is now awaiting the results of a UN economic study.

Estimates of the cost vary. The Indian government at present is settling for the lower end of the spectrum, suggesting that the scheme will cost
Rs 22,400 million, but figures as high as Rs 40,000 million have been put forward.

India's annual run off has been calculated at $1,672,600$ million cubic metres-about 2.5 times the run off from the Mississippi-Missouri basinbut 85 per cent of India's rain falls in the north in the summer. When the scheme is completed, the flood waters that fill the Ganges to bursting each summer will be tapped at Patna (see figure) and pumped at the rate of 60,000 cubic feet per second to the existing Sone barrage. Fifty thousand cubic feet per second will then be lifted along the Sone river for 150 days each year to the Bargi reservoir. Twenty thousand cubic feet per second will be released into the Narmanda river for the drought affected rivers in its basin, and the bulk of the remainder will flow to the Inchampalli reservoir. From there, 50,000 cubic feet per second will flow under the force of gravity into the Srisailam reservoir from which it will enter the

\section{The End is in Sight}

FISCHER played the Pirc Defence in the 17.th game of the World Chess Championship, a defence he has not been known to use before in a championship game. This demonstrates once again the thorough preparations that Fischer must have undertaken in the months preceding the match; in contrast, Spassky gives the impression of having taken this phase of the match rather too lightly in his pre-match training.

Spassky dealt adequately with the problems of Fischer's play, however, and at the cost of a pawn managed to work up a dangerous attacking formation. Fischer was obliged to give up the exchange in order to fight for a draw, a result he achieved surprisingly easily.

The 18th game was a fiercely fought Sicilian with both players again striving

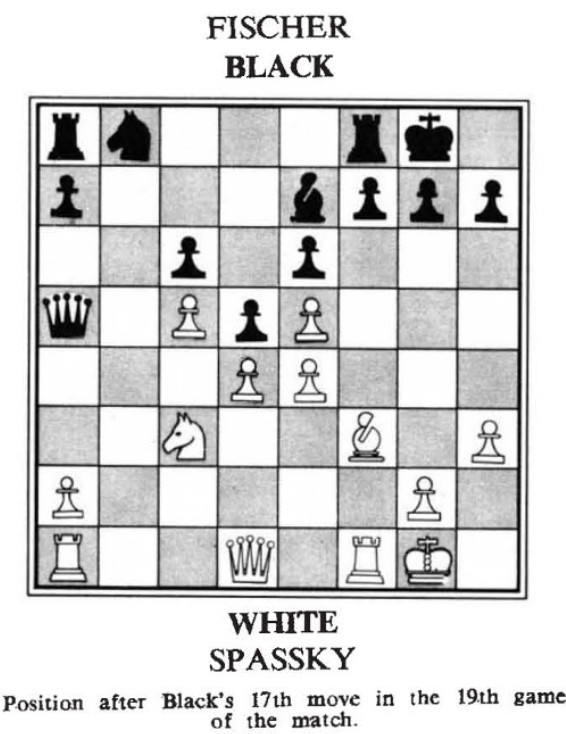

Pennar river and flow down to the Upper Anicut on the Cauvery.

In addition to the north-south canal, the construction of which will require driving a tunnel through the mountains south of the Bargi reservoir, a network of secondary canals will take water from the central one to help irrigate a yet wider area of the country.

Power needed to pump the water is estimated at 8.5 million kilowatts, but the natural slope of the rivers will be used to generate 2.3 million kilowatts of this total. Pumping will chiefly be limited to the 150 days during the monsoons when the flood waters in the Himalayan rivers will be used to generate cheap secondary power for pumping.

The scheme is not yet a certainty. If the second UN study shows it to be uneconomic then a major reconsideration of the project will follow, but if all goes well India may, by about the year 2000, have solved its chief irrigation problems.

for a win. A difficult game arose with queens and rooks on the board; Spassky was obliged to give up a pawn, but managed to pin down one of Fischer's rooks to the defence of his king in the corner. The position was fairly evenly balanced when the players repeated moves for a draw immediately after the adjournment.

The 19th game found Spassky on the white side of an Alekhine's Defence, but playing a variation against it superior to the one he had used earlier in the match. The game became rather lively when at the 18th move (see figure) Spassky made a speculative knight sacrifice. The play for the next few moves was highly tactical but Fischer found the right resources to fend off any danger. Indeed, Spassky was perhaps a little fortunate to be able to find a simplification to reach yet another drawn ending.

The play over the last six games or so has been evenly matched following Spassky's improved form, but Fischer, leading $11-8$, is now only a stone's throw from winning the match.-J.P.

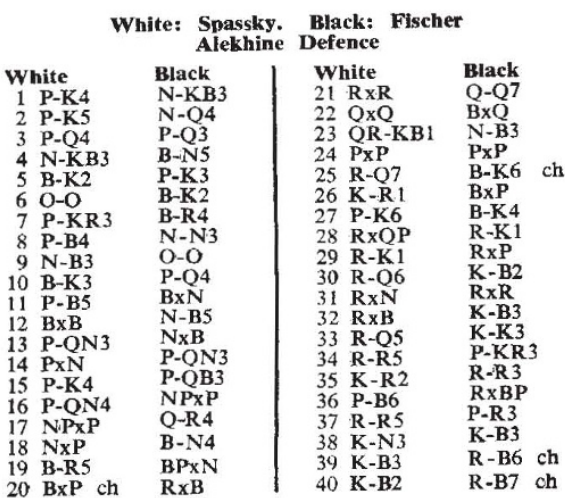

Drawn by agreement. 